\title{
El arte de la corrupción y la reconstrucción en el Libro de los venenos de Antonio Gamoneda
}

\author{
The Art of Corruption and Reconstruction \\ in Antonio Gamoneda's Book of Poisons
}

\author{
Ching-Yu Lin \\ Macau University of Science and Technology
}

\section{RESUMEN}

El presente estudio tiene como objetivo analizar la textualidad seudo-científica de la obra de Antonio Gamoneda, Libro de los venenos. El autor representa los discursos farmacológicos de la antigüedad adoptando la estructura científica. Sin embargo, observamos el arte de la corrupción en el corpus de la intertextualidad junto a las contradicciones de ideología y estética. Partiendo de la ruptura de lo original, llega a reconstruir nueva perspectiva con la que puede unir el registro informático al poético y reinterpretar los temas de las materias, la fórmula terapéutica y la ética.

Palabras Clave: Antonio Gamoneda; Libro de los venenos; corrupción; reconstrucción; poesía; ciencia; ética.

\section{ABSTRACT}

The present study aims to analyze the pseudo-scientific textuality of Antonio Gamoneda's writing, Book of Poisons. The author represents the pharmacological discourses of antiquity by adopting scientific structure. However, we observed the art of corruption in the corpus of intertextuality with contradictions in ideology and aesthetics. Based on the rupture of original textuality, new perspectives are established in which the informational register can be united to the poetic one. At the same time, material issues, therapeutic formula and ethics are reinterpreted.

Key words: Antonio Gamoneda; Book of Poisons; Corruption; reconstruction; Poem; Science; Ethics.

\section{INTRODUCCIÓN}

La temática en torno a la relación entre las ciencias y la literatura se ha tratado recurrentemente en los estudios contemporáneos sobre las artes, no constituyendo la literatura excepción alguna en este aspecto. A medida que la

Copyright: (C) 2016 CSIC. Este es un artículo de acceso abierto distribuido bajo los términos de una licencia de uso y distribución Creative Commons Attribution (CC-by) España 3.0. 
huella de las ciencias y la tecnología en el desarrollo y evolución de la vida de las personas es más profunda, escritores y otros artistas se han visto obligados a entablar un trascendental diálogo con los científicos sobre sus procesos creativos. Este diálogo, que se basa en la determinación de desmontar cualquier mecanismo radical, contribuye a fusionar de manera instintiva la clásica dicotomía entre sentido y sensibilidad, lo cual constituye una reflexión que tiene como objetivo expandir nuestra humanidad tratando de encontrar el equilibrio entre materialismo y espiritualidad. La ciencia se presenta como la respuesta a las crecientes necesidades de nuestra cada vez más compleja vida cotidiana, así como la llave que nos permitirá desvelar los más herméticos enigmas del Universo.

Caracterizada por su rigurosa objetividad, la ciencia tiende a clasificar los fenómenos y elementos que componen el entorno en el que vivimos, en otras palabras, dirige su mirada hacia el exterior desentrañando el misterio de cuanto nos rodea según unos parámetros objetivos y racionales. La literatura, por su parte, nos lleva hacia nuestro más profundo interior, hacia el reino de emociones e imaginaciones, el cual no se encuentra regido por la lógica analítica, sino por una exquisita sensibilidad hacia lo inexplicable. En el terreno artístico, los enigmas del Universo se ligan a la observación del santuario interno del alma humana, fuente de la virtud y la ética de las personas.

En esta época de feroz capitalismo en la que vivimos, el raciocinio científico es el responsable de la acelerada actualización de saberes, aportando de manera imparable nuevos descubrimientos y herramientas informáticas. Por ello, el lenguaje literario, a causa de la invitación que a través de él hacen los escritores a sus lectores a una reflexión sosegada y serena, parece ser incompatible con el discurso científico. Sin embargo, son numerosos los escritores que lejos de dar por definitiva la inviabilidad de aunar criterios científicos y artísticos, han tratado de romper esta aparente incompatibilidad desmontando creencias enquistadas por una larga tradición de oposición con ingeniosas propuestas.

Dicha incompatibilidad no sucede en la poesía de Antonio Gamoneda, uno de los poetas de la Generación del 50 más estudiados por los críticos literarios durante estos últimos años. La poemática gamonediana lleva la misión fundamental de representar las llagas biográficas e históricas desde un punto de partida fisiológico. Libro de los venenos (1995), la única obra al margen de la cuestión de los géneros literarios, sería un ejemplo maestro respecto de la unión de la ciencia médica y la estética. En este estudio nos proponemos desentrañar el enigma del bisturí neo-clásico con el que Gamoneda viene a rasgar el corpus físico y textual para intervenir las heridas de la humanidad. Nos interesa buscar unos indicios para responder a las siguientes dudas: ¿De qué manera se efectúa la táctica de descomponer el texto? ¿Cuál es el motivo por el que se resalta el sentido del materialismo de la naturaleza en el desarrollo de un discurso tan morboso como el del envenenamiento? Nos maravi- 
lla pero también nos inquieta el hecho de que el autor lleve a cabo la fórmula de corrosión en el sentido patológico y la de corrupción en el sentido metafísico. ¿Cómo funcionan las materias y sustancias mortíferas en ambos procedimientos? Evidentemente, la obra, al igual que el cuerpo humano, está sometida a numerosas operaciones para extirpar los tumores de la hegemonía cultural. Al final, dilucidaremos en qué forma se ofrece un pronóstico ético, que afecta en cierta medida a nuestra lectura de la textualidad racional.

\section{ENTRE ALIANZA Y ALTERACIÓN}

El Libro de los venenos presenta un saber empírico desde el que se observan las huellas del conocimiento. Dentro de ellas, aparece una interacción entre el absorber y el objetivar a propósito de los antiguos códices de botánica y medicina. Antonio Gamoneda recoge el libro sexto de La materia médica, escrito por Pedacio Dioscórides, el médico griego del siglo I. Andrés de Laguna, humanista segoviano del siglo XVI, lo traduce al castellano siguiendo la edición de Amberes de 1555 y añade sus comentarios. La obra, basada en la unión entre la escritura y la lectura, lleva como subtítulo Corrupción y fábula del Libro Sexto de Pedacio Dioscórides y Andrés de Laguna, acerca de los venenos mortíferos y de las fieras que arrojan de sí ponzoña. Con las citas de otros recursos de las sabidurías clásicas de Occidente y Oriente ${ }^{1}$, lo atribuimos a una recreación provechosa, que nos permite atravesar el tiempo y el espacio lejanos, y acercarnos a los archivos de instrucciones médicas de la Edad Media. A pesar del objetivo pragmático, en la «Noticia» que encabeza el libro, el autor admite que es el «puro vicio» el que le impulsa a constatar los nombres de su inspiración poética. Se vale del modelo convencional de la enciclopedia para recordarnos la existencia de la plataforma tradicional de nombres y términos, así como la forma alfabética adaptada en «Notas para un diccionario apócrifo» en Mudanza (1961-2003).

El concepto del vicio es esencial en las ideas creativas de Gamoneda, especialmente en el Libro de los venenos por la construcción de una intertextualidad $^{2}$ destructiva. Quizá el mencionado vicio aluda a la postura intelectual del biblioclasmo, que termina por desacreditar la escritura. Uno de los efectos viciosos de ello estriba en el saber fijo y muerto, que carece del contexto enunciativo, a saber, faltan las vías del diálogo (Ricaud, 2007: 45). El libro de Gamoneda, a su vez, acude a las cuatro voces narrativas de Dioscórides, Laguna, Kratevas y el narrador-poeta para informar a sus lectores del conte-

\footnotetext{
${ }^{1}$ Las fuentes son Plinio, Hipócrates, Nicandro, Galeno, Teofrasto, Aristóteles, Plutarco, Asclepíades, Virgilio, Avicena, el anónimo hispano-árabe, las Etimologías de Isidoro, el Lapidario de Alfonso X, Bernardo Gordonio, Claudio Eliano, el Physiologo Griego, el Bestiario de Cambridge.
} 
nido de otras escrituras. No cabe duda de que la voz de Gamoneda es la que domina y manipula todo el texto, aunque los comentarios de los antecesores sean de gran envergadura en el entramado argumental.

Ahora bien, es preciso averiguar la complejidad psicológica que posee el propio Gamoneda en el uso polifónico para confrontarse a sí mismo en una serie de contrariedades, tales como la de corrupción y plenitud, la de fábula y verdad. Las distintas voces, seleccionadas y organizadas por él, se distinguen en razón de los juegos tipográficos. En la «Nota a la edición» se explica así: «[...] en letra redonda los textos de Pedacio Dioscórides; en cursiva los de Andrés de Laguna; y en redonda y cuerpo menor los apuntes de Antonio Gamoneda» (Gamoneda, 1995: 17). Además, las voces no se imponen desordenadamente, sino más bien se constatan por cierto orden correspondiente a la autoría original. Y esto comprueba que lo que el poeta intenta mostrar es una praxis poética en vez de una esencia (Gómez Toré, 2006: 41). En una textualidad llena de «citas abusivas» $»^{3}$ y de pruebas científicas, la praxis puede ser atribuida a la regalía de transformarse, de recobrar lo antaño inventando, de acreditar o desacreditarse a sí mismo. A continuación, se produce la versatilidad de su propio dominio con la que acierta a «hacer un libro de una relativa frivolidad» (Calvo Vidal, 1996: 573).

¿En qué sentido el autor llega a cumplir el binomio de la voluntad creativa y la apropiación iniciativa ${ }^{4}$ ? Nos llama mucho la atención la alianza con la que insiste en una poesía movible y en una autoría indudable. Por lo que respecta a ello, Gamoneda confirma el valor de la autoridad, pero define a su propia manera la palabra de la confusión que influye en su ideología poética:

\footnotetext{
${ }^{2}$ Según Gerard Genette, hay cinco tipos de relaciones transtextuales: intertextualidad, paratexto, metatextualidad, architextualidad e hipertextualidad. En lo que atañe a la intertextualidad, se define como una relación de copresencia entre dos o más textos y, frecuentemente, como la presencia efectiva de un texto en otro (Genette, 1989: 10). La cita, el plagio y la alusión son tres formas aplicadas a la estructura intertextual.

${ }^{3}$ Gabriel Zaid trae a colación una frase del poeta Juvenal, utilizada para indicar la corrupción política: Quis custodiet ipsos custodes? (¿Quién vigila a los vigilantes?). El uso de las citas abusivas comienza con la preocupación por la distorsión. Aun así, desde la perspectiva posmodernista, se lo puede legitimar, ya que «todo autor es un segundo autor, todo texto es parte de un intertexto, no hay nada original» (Zaid , 2011: 280).

${ }^{4}$ La escritura formada a la luz de la apropiación textual resulta ser un tema fundamental para averiguar los cambios de la médula literaria. En su artículo, Fernando Rodríguez de la Flor estudia en profundidad los términos controversiales de plagio y apropiación, compuestos en la literatura contemporánea. A nuestro entender, lo que se debe cuestionar, en realidad, no es la polémica entre lo blanco y lo negro, entre lo original y lo copiado. En ellos observamos una concepción significativa con la que podríamos reflexionar sobre el impacto que causa la recreación del libro gamonediano en nuestra percepción. He aquí un párrafo en que la ideología del «saqueo» consistente y constante en beneficio de una especie de movilidad y popularidad permite interpretar el libro estudiado: «[...] la apropiación contribuye a que no se cierren, a que no resulten sagrados e intocables — por tanto olvidables_, pues los somete a una prueba de reactualización, desacralizándolos» (Rodríguez de la Flor, 2012: 77).
} 


\begin{abstract}
Yo pienso que la autoría es un hecho real... hay una cierta condición patrimonial, también, en virtud de la cual yo me puedo imitar a mí mismo, corregir a mí mismo y también apropiarme de lo de otro... Es decir, autoría, sí, pero los componentes de esa autoría no entiendo que sean obligatoriamente individuales... He podido transformarlas más o menos, pero se trata de una confusión que me interesa en el sentido más profundo de la palabra «confusión», es decir, que lo tuyo pueda ser mío... Además, hay un fenómeno parecido en la lectura, ¿no? El lector se convierte en un creador simultáneo (Agudo Ramírez, 2006: 33).
\end{abstract}

Se trata de una confesión sincera de un lector-escritor quien se encuentra en la confluencia cultural sin que se le prive del derecho a crear su propia contextualidad $^{5}$. Aparentemente, la confusión puede ser comprendida como una osmosis, un procedimiento imprescindible para ahondar en la diacronía y la sincronía, de ahí una escritura rebosante de «resignificaciones» y de «metáforas de la modernidad» (Suñén, 1996: 21). Conviene decir que se construye una biblioteca de la ciencia universal en la que el autor se afana por mostrarnos las huellas de su lectura y de su inseguridad, que a la postre nos contagiarán a nosotros los lectores. Y esta heterogeneidad y el hipergénero en el Libro de los venenos, efectuados mediante el diálogo de autoridades, una interacción entre alma y palabras, resulta ser un acto de leerse a sí mismo y un sinfín de revisión espiritual. Por lo tanto, la forma de la supuesta confusión acaba siendo el consuelo para el autor.

La intertextualidad de esta obra aparece como una dimensión beligerante en la que tras ejercer una «poética de la alteridad» (Saldaña, 2006: 130) el autor nos da a conocer los «collages oportunistas» (Gamoneda, 2004: 11) y la libertad de la capacidad de corrupción. A través del recorte y el suplemento reiterados, la lectoescritura cuenta con una teleología para exponer sus propios puntos débiles a propósito de la funcionalidad de la recreación textual: la inverosimilitud, la precariedad y la imposibilidad de hacer un libro definitivo. Ese prurito aparente de explicitar las definiciones de hierbas y sustancias se torna en «la figura detestable del melancólico animal de letras» (Rodríguez de la Flor, 2004: 170). Por ello, Gamoneda hace una reforma del registro del lenguaje interior, incorporándose al pensamiento estético, como las primeras palabras con las que explica el origen de su corrupción:

Pues bien, tengo que declarar «corrupción» porque yo he desviado la lengua de Laguna al profundizar en su rhythmic; tengo que declarar «fábula» porque la ciencia empírica y el galenismo están (al día de hoy, quiero decir) en su natural destino, que es poesía; y también porque yo he hecho obra de ficción inmoderada al pensar los venenos en los cuerpos y los espíritus (Gamoneda, 1995: 12).

${ }^{5}$ En su estudio relevante, Francisco García Jurado sostiene que el texto de Gamoneda es fundamentalmente el producto de una lectura. «Él mismo es lector que media entre los textos que le sirven de fuente y sus propios lectores, y en alguna ocasión da muestras de su lectura previa anticipándose a lo que después dirán Dioscórides y Laguna» (García Jurado, 1997: 383-384). 
Nos permite interpretar este pasaje con las ideas de Derrida. A la escritura se la tilda de hijo rebelde, que pretende alejar al padre y emanciparse, lo cual pasa a ser una subversión parricida (Derrida, 1975: 113-114). Digamos que el texto de Gamoneda se alimenta de esta rebelión invisible para levantar su espectacular altar. Ahí está su escenario y episodio en que se envenena el organismo establecido con el farmacón criminal y a la vez beneficioso para inyectar nueva sangre de vida. Por ende, el enunciador nos recuerda al comienzo del libro: «El lector de este Libro de los venenos tendrá que decidir por sí mismo la especie de la obra que tiene en sus manos» (Gamoneda, 1995: 11). El autor prefiere retirarse del problema de género, opinando que «los llamados géneros no son otra cosa que poesía diversamente preparada» (1995: 12). Sea como fuese, no se libra de la lectoescritura categorizada por la tipografía, que consiste en signos explícitos y una barrera por la que el lector se entera de dónde están los límites. ¿Acaso es una especie de lectura que viene a atestiguar el protagonismo relevante del lector por medio de las intrigas enciclopédicas de nombres acumulados pero posiblemente falsificados? Así, esboza el perfil de un lector ideal, la otra identidad del autor y la nuestra, sometidas sin querer al sistema alfabético y taxonómico. ¿O es una especie fantasmagórica que constantemente advierte la pérdida universal de sensibilidad a los escritores enjaulados y lesionados sin darse cuenta? La respuesta la tiene cada lector, pero en la medida en que se va adentrando en la lectura, la extrañeza y la alteración son cada vez más intensas, de ahí la salvación para Gamoneda.

Apropiándose de imágenes de letras, el autor representa las perspectivas de los demás escritores citados sin perder su propia voz. Se efectúa la negatividad, reacio a avalar por completo la escritura ajena de materias. Por lo demás, la refutación resulta ser contagiosa entre los maestros botánicos constatados. Tomemos como ejemplo el discurso del humanista Laguna, uno de los autores que «más contenido léxico ha proporcionado al Diccionario de Autoridades» (Gamoneda, 1997: 130); al expresar sus opiniones del licor del cárpaso, se afirma en estos términos: «Fue causa de muerte a muchos, según nos testifica Galeno en el primer libro de los antídotos». En cuanto a las señales del perro rabioso, tema no desconocido por el lector moderno, Laguna vuelve a hablar de los códices de Galeno, pero esta vez indica sus errores: «Escribe Galeno que de todos animales suele rabiar solamente el perro, pero vemos lo contrario por la experiencia» (1995: 146). A pesar de ello, el libro termina con la enunciación juiciosa de Laguna en la que nos advierte tanto de la inexactitud del discurso como de la posible calumnia hacia la escritura:

[...] pienso que no faltarán algunos que calumnien y motejen esta honesta fatiga sobre Dioscórides, aunque en ello me ofenderán muy poco, hallándome armado y apercibido de inexpugnable paciencia, la cual, contra las serpentinas lenguas de detracciones y maldiciones [...] Del resto, no me queda decir otra cosa sino amonestar a los lectores cándidos y benévolos que si en todo este discurso nuestro hallasen algo no bien tratado como fuera de razón, lo atribuyan a natural flaque- 
za, y de lo que fuere bien discutido den la gloria, el honor y las gracias al Omnipresente Dios, Padre, Hijo y Espíritu Santo, del cual manan toda virtud y toda industria. (1995: 211-212)

Curiosamente, Gamoneda pone el subtítulo «Fin» para que Laguna haga de su parte una «conclusión inconclusa» ${ }^{6}$ desde la que aún no se argumenta un desenlace. Además, parece iniciar una cuestión ética, procedente de la del lenguaje, declarando que las palabras poseen sus defectos innatos, de ahí que surjan desafectos mutuos entre los hombres. El humanista de la época renacentista alude a una alianza diacrónica, al tiempo que pronostica las lesiones que padecerán los letrados futuros por las palabras manipuladas en el momento en que se leen y se recogen. Así, el lenguaje de Laguna, caracterizado por una «versatilidad y disipación textual anticiceroniana» (Palomo García, 2007: 241), le concede a Gamoneda una doble dimensión elástica donde se pueden multiplicar actos, movilizar materias y mudar los cimientos. Huelga decir que el comentario de Laguna con respecto a la tesis de Dioscórides se convierte en un recurso fundamental para colaborar con el autor en las aventuras de errar y replicar.

A la larga los conocimientos científicos no son el objetivo del libro, sino más bien el medium por el que se conoce que «la ciencia médica arcaica ya no es ciencia sino poesía» (Gamoneda, 2004: 11). Quiere decir, la razón médica forma parte de la estética o viceversa. En consecuencia, no importa el hecho de que desaparezca la voz de Gamoneda en el «Fin», ya que declara por adelantado el papel de colaborador que desempeña: «Soy parte del Libro Sexto de Dioscórides y Laguna» (Gamoneda, 1995: 45). Los códices de Dioscórides y de Laguna no son meras lecturas, sino más bien relecturas de su alter ego, ocultados en las sombras históricas. El acto de identificarse con la textualidad heterogénea ${ }^{7}$ de la tóxica y terapéutica simboliza precisamente la corrupción literaria y la reconstrucción estética.

De repasar los comentarios a Dioscórides por parte de Laguna, se nota una estética menos escolástica con la que plantea sus escritos. «Laguna recurre habitualmente a anécdotas, relatos de experiencias propias, leyendas de países lejanos, etc., con el objetivo de hacer la lectura más asequible y amena a los no especialistas» (López Muñoz y Álamo, 2007: 200). Lo comprendemos por la definición de la fábula a la que se refiere Gamoneda: «Fabulosa por su belleza y por su mentira» (1995: 12). Obsérvese el diccionario apócrifo de Mudanza en el que se ejerce la técnica de alteración, y por qué no, la tecnología científica falsa, los términos específicos no se ven definidos pasivamente, más bien, obtienen la «función generativa» (Muleiro, 2004: 18) de transformar las etimologías informáticas en algo humorístico y humanístico. Dentro de ello encontraremos la dependencia de la materialidad, la angustia de los letrados y la transgresión del formalismo convencional.

\footnotetext{
${ }^{6}$ «No sé cuándo esta serie, parcialmente inédita, querrá cerrarse. Tiene su origen en mi convicción de que el lenguaje arcaico se ha "cargado" estéticamente» (Gamoneda, 2000: 15).
} 


\section{MATERIALISMO VISIONARIO}

La corrupción textual encierra una manifestación de la pasión por el cuerpo inevitablemente decrépito del ser vivo. Todas las obras poéticas de Gamoneda revelan la misma intimidad tenebrosa con la corporeidad. En la del $\mathrm{Li}$ bro de los venenos se nombran las materias nocivas con empeño hasta el punto de que sus lectores se vayan adaptando a las diversas referencias de la terminología toxicológica. En el «Prefacio» el poeta insinúa la toxicosis crónica ocasionada tanto en el cuerpo textual como en la perceptibilidad de lectores: «Fue común opinión de los antiguos médicos y philósophos que de tal suerte una persona se podría acostumbrar al veneno comenzando a comerlo en cantidad muy pequeña y acrecentándola después poco a poco, que al fin se sustentase de él como de familiar y loable mantenimiento» (Gamoneda, 1995: 3940). La razón por la que el poeta aprecia las sustancias en la escritura es la posibilidad de definir una y otra vez ciertas materias en detrimento del cuerpo humano. A través de las reiteraciones nominales el poeta analiza las formas y las sustancias interiores de los venenos, aclarando los malentendidos y presentando anécdotas relativas a ellos. No obstante, lo que realmente aporta el libro son otras materias visionarias adheridas a las palabras, utilizadas en la textualidad del recetario falsificado. En palabras de Jacques Ancet, nos hemos de centrar en la «secreción del tejido verbal mismo» (2000: 15), compuesta en el organismo que rige los actos de clasificar y clarificar.

El poeta hace hincapié en el «materialismo visionario» ${ }^{8}$ caracterizado en su poética. Lo averiguaremos a partir de dos puntos de vista: el de la razón de significar y el de la técnica de poetizar. Con la soberanía de las palabras, cada vez que se pronuncia el nombre de un objeto, el enunciador se aproxima más a la naturaleza epistemológica de la materia, puesto que hay un saber vivo, una sabiduría sentimental y una interioridad completamente material, más allá de la exterioridad visual de las hierbas y fieras referidas. Obsérvese un ejem-

${ }^{7}$ La obra de Gamoneda corresponde a las características del género misceláneo del siglo XVI. Este consiste en un conjunto de heterogeneidades, fuentes y referencias de otros autores, en busca de materias curiosas y exóticas. Así, tiene por objeto asombrar y extrañar a sus lectores, sirviéndose de una variedad de cosas y abundante información. Como se prefiere la cantidad maravillosa a la profundidad de conocimiento, el tono narrativo aparece menos severo y se parece a la conversación. Con todo, la frivolidad caracterizada en las misceláneas no supone una cualidad peyorativa, sino más bien un cambio de perspectiva y actitud de las masas hacia la cultura. La gente empieza a «consumir irreverentemente la cultura, a usarla y a traficar con ella sin ninguna prevención injustificada» (Alcalá Galán, 1996: 15).

${ }^{8}$ En el reportaje realizado por Tulio Demicheli, Gamoneda señala que más que un soñador, es un materialista visionario. Véase Demicheli, Tulio (2007). «Antonio Gamoneda: Más que un soñador, yo soy un materialista visionario», $A B C$ [en línea], el 22 de abril, disponible en: http://www.abc.es/hemeroteca/historico-22-04-2007/abc/Cultura/antonio-gamonedamas-que-un-so\%C3\%B1ador-yo-soy-un-materialista-visionario_1632677161880.html [ref. de 30 septiembre 2015]. 
plo notable en la introducción del hydro, cuyo nombre procede del griego, animal que vive en el agua. El hydro segrega una materia negra de olor detestable, que puede corromper la textura cutánea. Gamoneda selecciona la paráfrasis de Laguna sobre la hydra, la hembra de la misma especie, cuya mordedura perjudicará la memoria del herido. A esto se añade una fábula que inspira en general a los literatos, relatando que el nombre se encarna en imágenes folklóricas:

Fingieron los poetas que la hydra tenía muchas cabezas y que, cortada una de ellas, renacían otras en su lugar. Tomó principio esta fábula de cierta mujer aguda llamada Hydra, la cual solía preguntar tan dificultosas cuestiones que, averiguada una duda de ellas, se descubrían detrás muchas otras mayores (Gamoneda, 1995: 178).

En dicho fragmento, ciertamente no nos detenemos en el origen del término, pero las apostillas que agregan las palabras para descomponer su propia textura nos sobrecoge en gran medida. La fábula insertada parece ser el oropel con el que se envuelve un caramelo venenoso para llevar a cabo la corrupción textual. No obstante, también es esta divagación fabulosa la que circula por la sangre de todo el cuerpo y agudiza nuestra sensación acerca de la materia.

Las plantas y fieras malignas en boca de los autores predecesores buscan la identidad tradicional, en tanto que ellos tienen muy presente esclarecer los orígenes lexicológicos. Por lo que concierne a ello, la facultad de informarse de las materias resulta ser una mentira sumamente eficaz. Tras citar un fragmento de explicación de Dioscórides en torno a la hierba llamada eléboro, Gamoneda nos muestra su entusiasmo científico, indicando en estos términos: «siendo la yerba tan asistida en sus diversos nombres, no estorbará que aún nos detengamos en ella» (1995: 132). El empeño en reiterar diversos términos de la misma especie equivale a la perseverancia de los científicos al llevar a cabo repetidamente experimentos adecuados para confirmar las subsecuentes inferencias. Es menester comenzar con significados y paráfrasis del término, provenientes de distintas interpretaciones culturales. Cuanta más ansia se posea en aras de perseguir las huellas de los nombres, más ilusiones se producirán a propósito de la unidad material. Por consiguiente, el discurso se atrofia y termina elaborando un nuevo arte de la mirada. En este punto, Miguel Casado destaca la necesidad imperiosa de concienciarse de la deficiencia junto a la inexactitud permanente con respecto a la evolución científica:

Libro de los venenos muestra un continuo afán de clasificar y ordenar sustancias, acciones y reacciones; pero también de modo continuo se sumerge en las reiteraciones y las pérdidas, en los saltos y vueltas atrás, comprobándose cómo la forma de asociar ideas y conducir un pensamiento que propone el racionalismo moderno no es una fórmula universal y al margen de dudas. Aquí nunca se separa lo científico de lo falso (2009: 94).

El motivo por el que Gamoneda se precipita a proveer al materialismo una serie de significados es precisamente el de observar el engaño o desengaño que 
afecta de modo consistente a las apreciaciones anteriormente formuladas. Y esto no está lejos de la teoría de la geometría fractal, propuesta por el matemático Benoît Mandelbrot en 1975. En la dimensión matemática el pensamiento fractal se refiere a la autosimilitud en el sistema caótico. Parece que las configuraciones se diferencian, pero en realidad están hechas por imitaciones. Por lo tanto, por más variable que parezca el significado de una materia, nunca faltarán el sentido de carencia y la tendencia a la homogeneidad. Merced a la teoría del caos, la ciencia, incapaz de descubrir la plenitud del universo material, se empareja con la poesía, inclinada al abismo de lo infinito. Por lo tanto, «el poeta se aproxima a la ciencia con decisión, el físico a la poesía con respeto y celebrando el encuentro» (Janés Nadal, 1998: 109). Un poema coleccionado en Canción errónea de Gamoneda lo resume a la perfección: «En confusiones blancas, / cesan los números. / No / hay unidad / En las tumbas vacías / flota la ausencia y, / en las últimas celdas, / un dios incierto hunde sus manos y abre / la herida de los límites. No / hay cifras vivientes. / Sólo / la falsedad es sagrada» (Gamoneda, 2012: 45-46).

El materialismo, incierto y fluido, que no sugiere sino la capacidad del límite, es el que le impulsa al poeta reconstruir la estética neoclásica de «poetizar las disciplinas»" (D'Angelo, 1997: 17). La clave de poetizar la escritura taxonómica reside esencialmente en un contexto repleto de musicalidad. En su estudio, Ildefonso Rodríguez pone énfasis en el elemento de la prosodia, que encierra la polifonía de los tratadistas, la ampliación de sonoridad y de sentido (1996: 210). La sonoridad se remite a tres sectores: el del entramado rítmico, el de la etimología antigua y el de la grafía. En la entrevista, Gamoneda señala que siente la puesta en valor de componentes musicales en la lectura de Andrés Laguna (Rodríguez, 2008: 75). Dicho de otra manera, la polifonía dialogante pasa a ser un espectáculo en que se presentan números musicales de distinta índole. Pese a las objeciones que se interponen en las actuaciones, dado el ritmo idóneo al que enuncian y responden, entre los compositores ya no se distingue uno de otro. Los turnos verbales y las acciones sonoras acaban entretejiendo el placer verbal. En un momento dado, el ritmo expresivo sustituye al conocimiento científico en beneficio de un predominio de la lectura, de modo que ésta nos transporta a una nueva dimensión estética. Hay un

\footnotetext{
${ }^{9}$ Recordemos que el romanticismo alemán intenta acceder a distintos ámbitos para superar los límites del saber. Abogando por la irracionalidad de todo lo existente, los románticos atribuyen la física y la biología a las ciencias humanas, relacionadas con la vida y el alma. En lo que se refiere a ello, surge una distinción entre la forma mecánica y la forma orgánica. Esta es innata, se despliega desde dentro hacia fuera, mientras aquella se desarrolla por medio de influjos exteriores, a saber, desde fuera hacia dentro (Wellek, 1959: 60). El acto de conocimiento debe empezar por la reflexión interna para englobar finalmente el objeto y la otredad. Schlegel indica que «la elevada ciencia de la auténtica crítica le debe enseñar cómo formarse a sí mismo en sí mismo y sobre todo le debe enseñar a comprender toda otra forma autónoma de la poesía en su fuerza y perfección clásica» (Schlegel, 2005: 33).
} 
párrafo de Laguna en que se refiere a los hongos, reiterando específicas palabras clave y refinando las oraciones con rimas:

Todos los hongos, por escogidos que sean, si se comen sin discreción, dan la muerte ahogando. Siendo de naturaleza esponjosos, luego que entran en el estómago beben en sí todos los humores que hallan, con los cuales se hinchan de tal manera que ni pueden ir atrás ni adelante, y, así, comprimen los instrumentos de la respiración, y por este respecto, impidiendo el anhélito, ahogan. Además, se dan suertes de hongos que no sólo con su cantidad, sino también con su cualidad venenosa despachan, y de esta naturaleza son todos los verdes, los azules y los violados, porque no sólo se hinchan comidos, sino que también se corrompen y, corrompiéndose, corroen los intestinos, $\mathrm{y}$, al fin, arrancan el alma. Por donde el verdadero remedio es no gustarlos, sino tenerlos por sospechosos pues traen la muerte consigo (Gamoneda, 1995: 96-97; los subrayados son nuestros).

Jonathan Mayhew indica que el humanista emplea la figura de homeotéleuton, la igualdad de los sonidos finales, así como las palabras de «ahogan» y «despachan», para hacer una conclusión inexorable de que los hongos traen la muerte (Mayhew, 2009: 114). Aparte de ello, a nuestro juicio, la enunciación no descarta el principio del orden, requerido en las disciplinas científicas. Junto a ello se yuxtaponen palabras de acuerdo a la homofonía y a la formación verbal para activar los efectos imaginarios, como las palabras de «corrompe», «corrompiéndose» y «corroen». Nos repercuten profundamente la asonancia y la melodía, asociadas a visiones tenebrosas de las plantas.

En cuanto a la etimología, la anotación de la sierpe llamada «hemorro» es uno de los ejemplos más reveladores: «Hemos, en griego, quiere decir la sangre, y roos el flujo» (Gamoneda, 1995: 174). Se otorga un significante junto al escenario vívido en función de la estructura fonética. La misma palabra se la explica disgregando sus sílabas para representar la consecuencia que trae la fiera. La grafía, a su vez, puede considerarse una dosis efectiva para embriagar a los lectores en la lectoescritura, así como las palabras de amphisbena y phalangios. El mismo efecto sonoro lo encontramos en la palabra toxon, saeta uncida con licor que utilizan los griegos para matar a los presos. Los árabes denominan el veneno «tusom». Recurriendo al dictamen de Laguna, Gamoneda exhibe la asimilación fonética, como una forma de disolución verbal: «Sirve también a confirmarnos en esta opinión la gran afinidad de los nombres, porque este vocablo, tusom, parece corrompido de toxon» (1995: 89). Lo que realmente acierta a explicitar los caracteres procedentes de distintas culturas es la estructura interior, la de la rima reiterativa de la dicción. Es decir, en la estructura interior los términos se ven definidos repercutiendo y templando.

En las críticas de sustancias, se reforma el modelo convencional de análisis y denotación. Merece la pena leer las palabras de Kratevas, que trae a colación la idea de Cleodemo sobre la sal euxina en el mar:

Hablaron del color dorado de la sal euxina, debido tanto a la declinación boreal de la luz como a las sortijas que sobre la desecación en sus lagos producía el la- 
tido del mar en la materia blanca, pero que al fin era arte de la mirada ya que el color no estaba en la substancia. Y dice Kratevas que, en las palabras de Cleodemo se alcanzaba una celebración de la vida, aclamando que la apariencia de la sal no fuese emanación fría de la naturaleza sólida, sino propiedad del órgano cuyos suaves tejidos permiten que el fuego interior pase a su través y, siendo más fino que las aguas oculares, reúnen los espíritus del hombre que mira con los de las cosas, obrándose así la existencia de un fluido en el que la belleza participa con sus átomos (1995: 191).

Cobra gran importancia el discurso relativamente paradójico con respecto a la razón y los métodos científicos con los que se muestra la forma y estructura de una materia. En la medida en que se va denotando la exterioridad del objeto con la écfrasis retórica, el lenguaje conduce a la dirección inversa de manera inesperada para connotar tanto su proceso de materializar como su empresa de desmaterializar. En otras palabras, se ejerce magistralmente la «alternancia entre hermetismo y claridad» (Muleiro, 2004: 8 ) $^{10}$ a fin de demostrar el complejo del corpus expresivo en que se encuentran todas las sustancias.

\section{De la terapéUtica A LA NUEVA ÉtiCA}

El término de fármacon ocupa el lugar más destacado de toda la obra, definiéndose en estos términos: «El veneno en griego se llama phármaco, y este es nombrar común a las medicinas santas y salutíferas y a las malignas y perniciosas, pues no hay veneno tan pestilente que no pueda servir en algo a la sanidad» (Gamoneda, 1995: 34). En una palabra, el fármacon es remedio y veneno al mismo tiempo. Como lleva el sentido de «filtro», se introduce en el cuerpo del discurso con su ambivalencia (Derrida, 1975: 102). Tanto los tósigos como los antídotos forman buena parte del lenguaje de la conciencia, con el que se muestran las respectivas realidades clínicas. En vez de fijarse en un mero efecto, el discurso presenta sus propias inestabilidades, tales como el informar de lo negado o el negar lo confirmado. Por consiguiente, la frontera del desdoblamiento funcional de lo benéfico y lo maléfico de las sustancias desaparece. El libro, renuente a confirmar el único teorema que se descubre de acuerdo a una metodología racional, nos muestra su resistencia a la hegemonía cultural de la ciencia. Tomando esta postura, el poeta trata de ambientar la ceremonia en homenaje a la muerte con el esteticismo de la ambigüedad. Partiendo del arte de envenenar, se origina el arte de sanar de ciertos malestares. Con los saberes sobre el veneno de los que el libro informa, se expone el estado acribillado del cuerpo textual o del cuerpo humano, lo cual

${ }^{10}$ El prologuista menciona que Gamoneda conserva algunas características de la Generación del 27, como por ejemplo, las de «la apropiación del conocimiento técnico de la lengua, la valoración del esfuerzo más que de la gracia ante las demandas de la poesía, las idas y vueltas por los registros culto y popular» (Muleiro, 2004: 8). 
no es una ficción, sino una realidad de la existencia. Así, no es extraño que el poeta sostenga en la Descripción de la mentira: «Es perverso el idioma pero es enjundia de mi cuerpo» (2004: 188).

Hay que aclarar que se ofrece el tratamiento no solo en sentido de «farmacón» sino también en un sentido lingüístico-terapéutico. Los métodos curativos no se realizan sino mediante la expresión de la «pasión química» y sustancial por la inmovilidad cadavérica en la eternidad. Por ello, valiéndose del registro del lenguaje perverso, comienza por revelar la visión fisiológica del cuerpo-objeto de los agonizantes, imágenes que se crean como algo exterior. Empero, seguidamente, se va tornando en el cuerpo-sujeto, el «yo encarnado» que desempeña el papel de un «ser sintiente» (Marcel, 1956: 238), en lugar de un ser sentido instrumental ${ }^{11}$. En Gamoneda es esta subjetividad encarnada la que receta por su propia cuenta la «triaca» contra la apostema visceral que a ella misma la tortura. Enumeramos el siguiente pasaje de la escritura de Kratevas, que relata minuciosamente el cuerpo-sujeto o el llamado «protosentir», sumergido en el «sentir fundamental» por el efecto de los hongos asiáticos.

Entonces, mis visiones entraron en mudanza: sentí ríos anchos y profundos en los que mi cuerpo era uno con su caudal, y en ellos pude llegar a una tierra blanca y carente de sombras, que, siempre en silencio, fue poblándose de animales sin especie y de seres humanos cuyos rostros eran y no eran los de algunos muertos amados (1995: 103).

El cuerpo es lo que cuenta y realiza la mudanza mental al tumor latente de la memoria melancólica, un auto-descubrimiento y un auto-análisis relevantes. Tal vez lo que le preocupa al autor no es más que el modo en que uno siente los cambios corporales en aras de verificar el cuerpo tan propio como el suyo, el espacio sumamente expresivo como el de su diagnóstico basado en la terapéutica clásica. Es oportuno decir que en la obra gamonediana el lenguaje científico es inocente (Sánchez Santiago, 2001: 118), puesto que se exhibe no para formular un medio instrumental ni para recoger el objetivo político. En cambio, se desarrolla una ciencia personal e íntima, unida a la sabiduría posiblemente imprecisa, para mostrar este «gemido inútil» (Gamoneda, 1995: 173), tal y como el verso que se escribe: «Hay una salud que sucede a la desesperación»(Gamoneda, 2004: 181).

Ahora bien, los venenos mencionados no solo se reconocen como materias para hacer visible la muerte, sino también el conjunto de los síntomas de

${ }^{11}$ Cabe acentuar la importancia de la corporalidad que acompaña a los objetos y materias en todo el libro con la finalidad de descifrar el palimpsesto textual de Gamoneda. En Diario metafísico y El misterio del ser, Gabriel Marcel está a favor de la prioridad absoluta dotada en el cuerpo humano, señalando que para tener conciencia de la individualidad de la existencia hay que ligarse a la corporalidad. Lo que ciertamente puede iluminar el modo en que uno experimenta su cuerpo como el suyo reside en la subjetividad encarnada. 
cólera, por lo que «el alma sale de la boca» (Gamoneda, 2004: 542). Pero, ¿en qué consiste el ejercicio o tratamiento preventivo contra el atosigamiento? El autor nos deja constancia del concepto polivalente de los purgantes, que según Laguna funcionan como sustancias imprescindibles para remediar a los envenenados. La idea del purgar de las inmundicias, en efecto, connota tanto la liberación de la cólera y de la melancolía física como la purificación espiritual $^{12}$. En otras palabras, lo sórdido no se oculta en la carne, que lleva tiempo aguantando las desazones históricas, entre ellas el tumor de la dictadura franquista. A lo largo de esta especie de lectura en la que la degradación adquiere una nueva definición, el lector logra inopinadamente una dosis de lenitivo para gozar de la convalecencia transitoria. He aquí un pasaje en el que Dioscórides sugiere ejercer la evacuación de venenos:

Sin duda todas las enfermedades son igualmente curables o incurables, según el vigor de las causas y las disposiciones y habilidades del cuerpo, pero si los atosigados hubiesen perdido el habla, o estuviesen borrachos, o por no querer ser librados nos encubriesen la cualidad del veneno, en tal caso usaremos súbito de aquellas cosas que comúnmente son a cualquier tósigo útiles. Para lo cual no se hallará más que general remedio que la evacuación del tósigo por los más propincuos lugares antes que cobre fuerzas (Gamoneda, 1995: 24).

Para aquellos que pierden las palabras se les recomienda usar la terapéutica de purgación o evacuación, atribuida a la catarsis anímica que viene a recompensar el intersticio obligado a ser silencioso. En el caso de que la gente se vea privada del derecho a hablar, especialmente en la «dimensión mitriática», derivada de la autoridad de Mitrídates Eupátor, emperador al que Kratevas sirve con su especialidad botánica para acosar a sus enemigos, el texto, dotado del «carácter hipocondríaco» (Rodríguez de la Flor, 2007: 63) y del impulso de «vivir mejor» ${ }^{13}$, revela el secreto del trastorno colectivo, al tiempo que toma su propio cuerpo textual por un recurso sustancial en beneficio del experimento literario-curativo. En este mismo instante, se lleva a cabo «un proceso homeopático» (Lanz, 2007: 3) en el que lo enfermo se cura con lo que es similar. Con arreglo a las indicaciones de este método curativo menos científico, las sustancias diluidas aciertan a revitalizar el cuerpo de forma natural, al igual que el tratamiento de la sangría y el de la purgación. En la escritura

${ }^{12}$ Según Francisco López Muñoz y Cecilio Álamo, Cervantes trae a colación en el Quijote los purgantes mencionados por Laguna. Estas sustancias son «capaces de lograr la eliminación de los humores morbosos, permitiendo una purificación espiritual» (2007: 202).

${ }^{13}$ En Razones del cuerpo, Jean Starobinski insiste en que la ciencia es un valor fundamental, vinculado a otros valores que propician nuestra existencia. La medicina muestra la preocupación por salvaguardar la integridad corporal. Efectivamente, este objetivo de «vivir bien» representa nuestro «instinto de conservación» (Starobinski, 1999: 174). Aceptamos varios medios y recursos, oficiales o alternativos, para restablecer la salud, al mismo tiempo que llegamos a relacionar nuestra obsesión con la naturaleza, el curanderismo y los rituales mágicos. 
de Gamoneda, las palabras de los venenos se disuelven progresivamente en el agua de la memoria, produciendo una molécula preventiva. A fin de cuentas, el cuerpo lírico es un caldo de cultivo de bacterias que contribuye a la confección del tratamiento más eficaz para sanar otros cuerpos contra posibles infecciones.

Sin lugar a dudas, la ciencia médica de la antigüedad funciona por antonomasia en la lingüística-estética de la poesía. El lenguaje pronóstico apunta a ciencia cierta los procesos escalofriantes de la podredumbre corporal, al mismo tiempo que se mezcla con «la terrible dulzura de las palabras pronunciadas en la desaparición» (1995: 173). Dada esta dulzura verbal tan elocuente, los vértigos morbosos pasados se ven embellecidos. Después de envenenar a Kish, la criada de la madre del Mitrídates, Kratevas anota sus cambios físicos con admiración: «En la séptima vez, apareció oscuridad en sus labios y esto aumentaba su belleza. En siete días más, los huesos de su rostro se dejaban ver como frutas de sombra en la transparencia de la piel, y la visión morbífica era también belleza creciente en torno a los ojos, semejantes a los de una dulcísima bestia lastimada» (1995: 119). En este sentido, el narrador goza del placer de observar la consumición corporal, ignorando los juicios éticos tradicionales. A través de la detenida contemplación de cambios físicos del cadáver envenenado, la presencia de la muerte se convierte en una obra prodigiosa. Resulta que la razón metodológica de la ciencia se une a la acción artística prolongada para efectuar una nueva receta curativa.

En el jardín del temor se cultivan las bellas flores y plantas del mal, cuya fragancia anestesia a los inocentes, de ahí que se inicie una nueva ética. Miguel Casado encarece la administración de la muerte desde la que se abordan los temáticos paradójicos con respecto al pensamiento moral, y manifiesta que «es el humanista Laguna el que sitúa el origen del libro en la existencia del mal, en la enemistad del hombre con el hombre» (Casado, 2009: 96). Gamoneda también admite que sus exclamaciones «relataban la perdición y la enemistad» (Gamoneda, 2004: 177). Las experiencias clínicas del libro no se refieren exclusivamente a los conocimientos botánicos, sino también a las máximas de los tratos interpersonales; en ellos, la humanidad, la naturaleza, la civilización y la sociedad jerarquizada son temas secundarios. Laguna advierte en tono humorístico que los príncipes y los ricos deben tener más cautela para huir de los venenos, puesto que «los pobres pocas veces suelen ser asaltados por la semejante traición» (1995: 41). Hay un descubrimiento sugestivo de la relación intrincada entre los corazones incógnitos humanos y las asechanzas ocasionadas. La traición también puede pasar a los padres e hijos por los intereses de la sucesión, que «suele ser causa de parricidios abominables» (1995: 41). Pese a ello, las digresiones sobre la maldad se interrumpen en el registro científico de forma humanística para revelar la verdad. Además, pretende convencer a los lectores afirmando sin ambages la lógica presencia de la maldad: 
Si los hombres mantuvieran entre sí aquella fe y hermandad que se guarda entre las más feroces y bravas fieras, o si la naturaleza les diera el mismo conocimiento e instinto que recibieron de ellas los animales brutos, con el cual sienten luego lo que más les conviene y huyen siempre lo pernicioso, Dioscórides no tuviera ocasión de añadir este de los venenos mortíferos a los libros de su autoridad (1995: 32).

El poder de las palabras está en vigencia a raíz de delatar la propensión naturalizada a la crueldad y de reiterar las experiencias del límite o de negaciones con espontaneidad. El tratado psedo-científico propone el requerimiento de un cambio de paradigma ético y estético, una literatura de la moral otra (Saldaña, 2006: 130). Se exponen prototipos provocativos como otro poder alternativo para transformar el campo expresivo. Laguna, sobresaliente entre ellos, crea un resquicio intelectual para prevenir las artimañas empleadas por el instinto humano, refiriendo que «si el mundo fuera tan inocente que no supiera, para dañar al prójimo, ayudarse de tan infernales artes, estuviera excusada nuestra fatiga, mas como sea ya tan ordinario el atosigar y, así, en nuestros días, se atosiguen más fácilmente los hombres que los ratones» (1995: 33). Plinio, a su vez, sostiene que «con un traquillo lo hiciésemos sin pena y después de muertos no nos tocasen las fieras» (1995: 33). Empero, el libro termina con la advertencia de Laguna de que la fiera doméstica y familiar más virulenta de todas no es sino el hombre, «de cuya viperina lengua, a veces sin ser sentida, se derrama una ponzoña tan peligrosa y mortal que ni el metridato ni la triaca perfecta bastan para remediar sus daños» (1995: 211). No hay sustancias tan perjudiciales como las palabras hirientes. Si bien las voces mediadoras se ocupan de la crítica y de los discursos relacionados con el hombre, el poeta muestra sus preocupaciones con distancia a propósito del mundo o el cuerpo cada día más frío para defender del ardor agudo, causado por los venenos circunstanciales. Pese a su objetivismo que permite eludir una crítica egocéntrica, la pesadumbre y el desengaño frente a la cultura de la barbarie ${ }^{14}$ se ven intensificados por el arcaísmo apropiado, que nos parece una forma de retraimiento.

Las anécdotas intercaladas en las glosas científicas conforman un terreno

${ }^{14}$ Walter Benjamin hace hincapié en la barbarie en que uno se encuentra inmerso a la hora de presentar o representar una historia. Nosotros los receptores nos vemos subordinados por los materiales de que se vale el intérprete. Por tanto, se requiere una distancia de seguridad con la que se aleja de la cruel esencia del hecho. Lo explica en estos términos: «En el materialista histórico tienen que contar con un espectador distanciado. Ya que los bienes culturales que abarcan con la mirada, tienen todos y cada uno un origen que no podrá considerar sin horror. Debe su existencia no sólo al esfuerzo de los grandes genios que los han creado, sino también a la servidumbre anónima de sus contemporáneos. Jamás se da un documento de cultura sin que lo sea a la vez de la barbarie. E igual que él mismo no está libre de barbarie, tampoco lo está el proceso de transmisión en el que pasa de uno a otro» (Benjamin, 1989: 181-182). 
reflexivo donde el miedo y el desamparo humano conceden el sentido de la carencia humana. Y esto, quizá, es el origen desde el que ponemos en tela de juicio la cultura capitalista, inclinada a llenar los huecos de modo automático a fin de eliminar la conciencia de la pobreza. En el mundo clásico, los personajes buscan sus propios remedios con vehemencia. Recordemos un fragmento en que Laguna vio a dos romanos contendiendo sobre cuál tenía más probados remedios contra todo género de serpientes. La competición acaba con un clímax dramático en el que «el otro, por no quererse rendir, murió en su obstinación, aún rogándole el adversario que se dejase ayudar» (1995: 210). Obviamente, en Gamoneda se celebra por todo lo alto una visión atrevida sobre las pérdidas repetidas, incluida la muerte. Esta embriaguez por cualquier forma de acabamiento y de desaparición, en un momento dado, es igual que un estimulante que viene a alentar la mentalidad pasiva de la satisfacción, con la cual cesan el deseo y el placer (Schopenhauer, 1985: 136). Desde esta óptica, las fábulas vienen a promover el humanismo antimoderno, que insta rendir culto a un final espectacular ${ }^{15}$, la pérdida más insaciable de la muerte.

\section{CONCLUSIÓN}

Aunque el Libro de los venenos se caracteriza por la inestabilidad textual a la que algunos estudiosos agregan el valor de la ironía, este no posee la clave con la que se pueden descifrar los motivos narrativos del autor. Mejor dicho, con el principio poético de la contradicción, que él mismo no pretende (Calvo Vidal, 1996: 573), llega a reconstruir una estructura de la ruptura, de la otredad y de los límites. Por eso, sirviéndose de la técnica de corrupción, Gamoneda se apropia del lenguaje de sus predecesores para recrear un texto científico apócrifo donde lo incierto y lo inseguro preceden a la verdad inefable. Por lo demás, dadas las desviaciones y alteraciones de la intertextualidad informática, la razón crítica se transforma en el acto de poetizar. En este caso, la ciencia ya no representa la única funcionalidad analítica, sino más bien una parte de la práctica poética.

En las visiones materiales se observa el lenguaje poético, como por ejemplo, en las citaciones etimológicas, la musicalidad verbal, las plantas y fieras venenosas que se ligan a la existencia humana, los animales que acompañan en la vida ordinaria y en la fantasía mitológica, las sustancias que traen consigo los sufrimientos y recobramiento físicos, etc. Todos ellos son objetos que

\footnotetext{
15 «Conforme se avanza en el Libro de los venenos, su componente de fábula acentúa su protagonismo a vueltas de las historias que Gamoneda fabula sobre Kratevas, un virtuoso del envenenamiento que parece guiarse por el principio de que los envenenados tienen derecho a un final espectacular transido de hibridaciones entre dolores terribles, placideces excelsas y poesía» (Balcells, 1998: 234).
} 
relacionan el cuerpo-sujeto con el enigma y el peligro imprevisto de la naturaleza. Sin ellos no se siente la carne temblada ni la fragilidad corporal en los combates sucesivos a los que nunca podemos resistir. En resumidas cuentas, el materialismo gamonediano es tan real que nos desconcierta, es tan visionario que nos despierta.

En la reproducción o la apropiación textual de los tratados farmacológicos, Gamoneda simplemente transmite una lectoescritura sin juzgar los temas con subjetivismo. Empero, no es oportuno etiquetar su posición creativa con la autoría condescendiente, ya que el foco al que presta atención es la soberanía de las palabras poéticas, que domina en distintos campos intelectuales, incluso en el ámbito moral. Se desarrolla una operación compleja a la luz de las ideas caducas de Dioscórides, de Laguna y de Kratevas para realizar una autopsia fisiológica en la actualidad. Por ende, las recetas anticuadas vienen a interpretar nuestro mundo moderno, como si fuese un reflejo en que también somos víctimas y verdugos al mismo tiempo. De ahí un entrelazo inseparable entre las experiencias clínicas y la ética actualizada y reactualizada.

El cuerpo efímero a riesgo de marchitarse reivindica la conciencia de pérdida, el umbral central desde el que se accede al humanismo de un sujeto encarnado. Nos parece convincente llegar a la conclusión citando la ideología fenomenológica de Merleau-Ponty: «El cuerpo, como edificio químico o conjunto de tejidos, está formado por empobrecimiento a partir de un fenómeno primordial del cuerpo-para-nosotros, del cuerpo de la experiencia humana o del cuerpo percibido, que el pensamiento objetivo tematiza, pero del que no debe afirmar haber llevado a cabo un análisis exhaustivo» (1994: 363). El poeta es consciente de que es necesario corromper una y otra vez lo aparentemente original para reconstruir una pieza de lo verdadero, que solo aparece en un momento dado, y sabe perfectamente que ahí está el antídoto para la existencia y la presencia humanas.

\section{BIBLIOGRAFÍA CITADA}

Agudo Ramírez, Marta (2006). «Somos únicamente palabras. Antonio Gamoneda en conversación», Quimera. 275, pp. 26-33.

Alcalá Galán, Mercedes (1996). «Las misceláneas españolas del siglo XVI y su entorno cultural», Cuadernos de Filología Hispánica. 14, pp. 11-19.

Ancet, Jacques (2000). «El éxtasis blanco», Libro del frío. Valencia: Germania, pp.7-21.

Balcells, José María (1998). «Libro de los venenos o la voz múltiple de Antonio Gamoneda», De Jorge Guillén a Antonio Gamoneda. León: Secretariado de Publicaciones de la Universidad de León, pp. 231-237.

Benjamin, Walter (1989). Discursos interrumpidos I: Filosofía del arte y de la historia. Buenos Aires: Taurus.

Calvo Vidal, José Luis (1996). «Entrevista a Antonio Gamoneda», Moenia. 2, pp. 565-574. 
Casado, Miguel (2009). Curso de la edad. Madrid: Abada.

D’Angelo, Paolo (1997). La estética del romanticismo. Madrid: La balsa de la medusa.

Derrida, Jacques (1975). «La Farmacia de Platón», La diseminación. Madrid: Fundamentos, pp. 91-215.

Gamoneda, Antonio (1995). Libro de los venenos. Madrid: Siruela.

Gamoneda, Antonio (1997). El cuerpo de los símbolos. Madrid: Huerga y Fierro Editores.

Gamoneda, Antonio (2000). «Preámbulo», Sólo luz. Valladolid: Junta de Castilla y León, Consejería de Educación y Cultura.

Gamoneda, Antonio (2004). Esta luz. Barcelona: Círculo de Lectores.

Gamoneda, Antonio (2012). Canción errónea. Barcelona: Tusquets.

García Jurado, Francisco (1997). «Antiguos textos de ciencia convertidos en Poesía: Dioscórides y Andrés Laguna en el Libro de los venenos de Antonio Gamoneda», Epos. XIII, pp. 379-395.

Genette, Gerard (1989). Palimpsestos. La literatura en segundo grado. Madrid: Taurus.

Gómez Toré, José Luis (2006). «Un instante sin límites: Memoria y elegía en la escritura de Antonio Gamoneda», Quimera. 275, pp. 40-45.

Janés Nadal, Clara (1998). «La aventura (Ciencia y poesía)», Revista de Occidente. 207, pp. 96-110.

Lanz, Juan José (2007). «Antonio Gamoneda y la poética de la desocupación», Ínsula. 726, pp. 2-5.

López Muñoz, Francisco y Álamo, Cecilio (2007). «El Dioscórides de Andrés Laguna en los textos de Cervantes: de la materia medicinal al universo literario», Anales Cervantinos. XXXIX, pp. 193-217.

Marcel, Gabriel (1956). Diario metafísico. Buenos Aires: Losada.

Mayhew, Jonathan (2009). The Twilight of the avant-garde. Spanish Poetry 1980-2000. Liverpool: Liverpool University Press.

Merleau-Ponty, Maurice (1994). Fenomenología de la percepción. Barcelona: Península.

Muleiro, Vicente (2004). «Prólogo», Lengua y herida. Buenos Aires: Colihue, pp. 7-19.

Palomo García, Carmen (2007). Antonio Gamoneda: Límites. León: Universidad de León, Secretariado de Publicaciones.

Ricaud, Philippe (2007). «Contra el libro. El biblioclasmo como postura intelectual», Istor: revista de historia internacional. 31, pp. 42-82.

Rodríguez, Ildefonso (1996). «Azogue, sangre, leche alacrán: el libro de lo incierto», Espacio / Espaço escrito 13-14, pp. 209-215.

Rodríguez, Ildefonso (2008). «Una conversación con Antonio Gamoneda», Antonio Gamoneda. Madrid: Calambur.

Rodríguez de la Flor, Fernando (2004). Biblioclasmo: una historia perversa de la literatura. Madrid: Renacimiento.

Rodríguez de la Flor, Fernando (2007). «Presentación», Sílabas negras. Salamanca: Universidad de Salamanca, pp. 9-79.

Rodríguez de la Flor, Fernando (2012). «Apropiación y plagio en la literatura de la modernidad tardía», en Julio Ortega (ed.), Nuevos hispanismos del lenguaje dominante. Madrid: Iberoamericana, pp.73-105.

Saldaña, Alfredo (2006). «Poesía y poder en la España contemporánea», Iberoamericana. VI, 24, pp.121-132.

Sánchez Santiago, Tomás (2001). «La emoción de la exactitud», Zurgai. Diciembre, pp. 116118.

Schlegel, Friedrich (2005). Conversación sobre la poesía. Buenos Aires: Biblio.

Schopenhauer, Arthur (1985). El mundo como voluntad y representación, 2. Barcelona: Orbis.

Starobinski, Jean (1999). Razones del cuerpo. Valladolid: Cuatro. 
Suñén, Juan Carlos (1996). «Modernidad practicable: Filología y re-significación», Ínsula. 593, pp. 20-21.

Wellek, René (1959). «El Romanticismo», Historia de la crítica moderna (1750 a 1950), II. Madrid: Gredos.

Zaid, Gabriel (2011). «Citas exóticas, citas abusivas y citas acumulables», Revista de economía institucional. 14, 27, pp. 273-285.

Fecha de recepción: 29 de enero de 2014.

Fecha de aceptación: 10 de julio de 2014. 